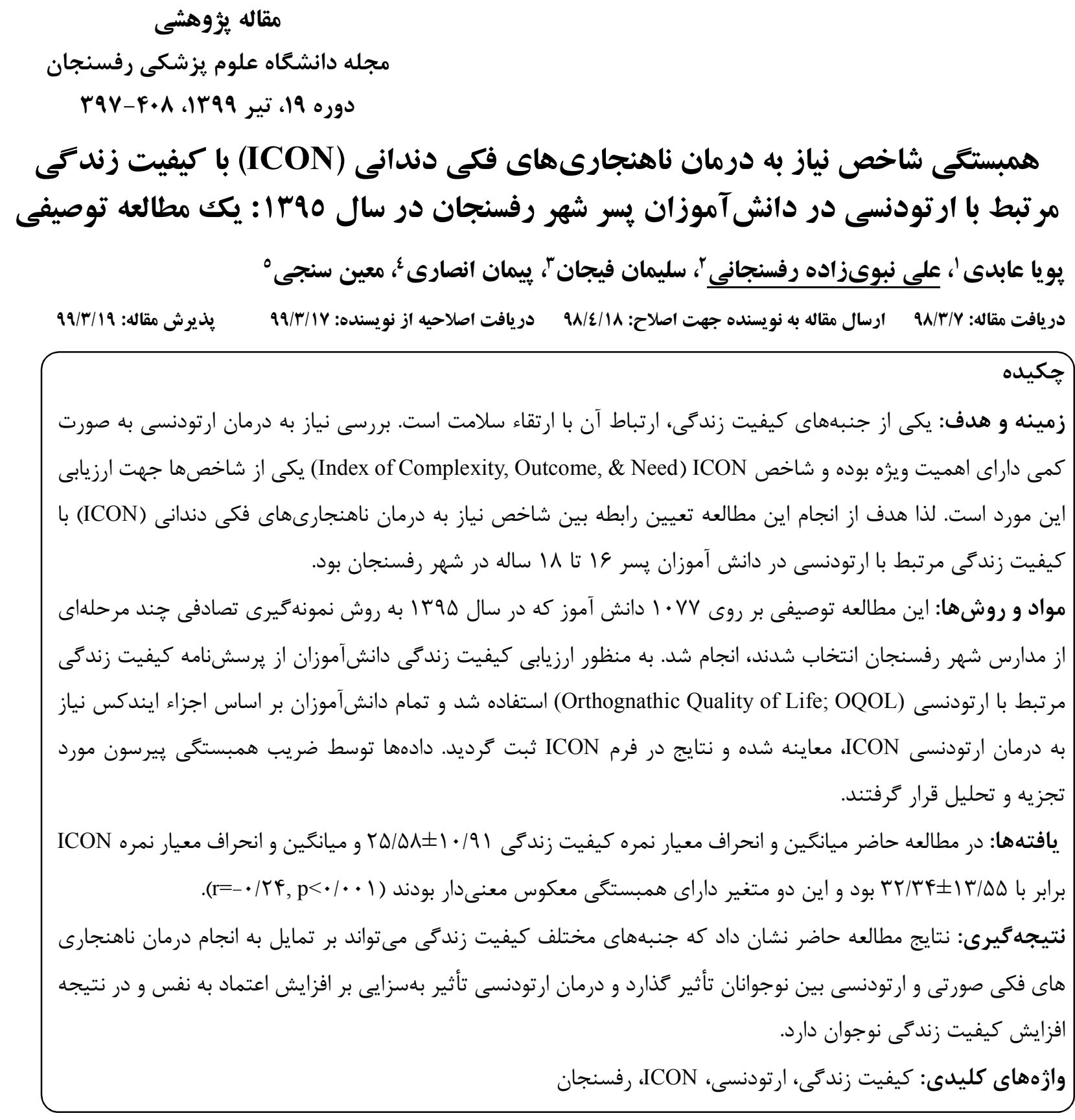

$$
\begin{aligned}
& \text { 1- دانشجوى دندانيزشكى، كميته تحقيقات دانشجويى، دانشكاه علوم بزشكى رفسنجان، رفسنجان، ايران }
\end{aligned}
$$

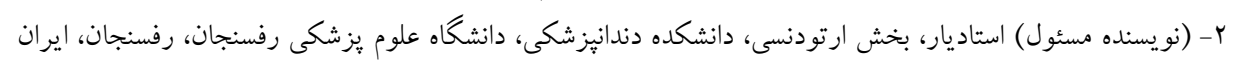

$$
\begin{aligned}
& \text { تلفن: Flinabavizadeh@gmail.com }
\end{aligned}
$$

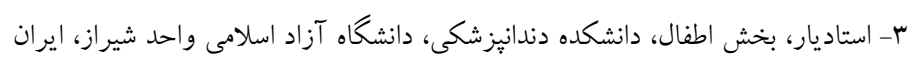

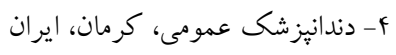

$$
\begin{aligned}
& \text { ه- دندانيزشك عمومى، كرمان، ايران }
\end{aligned}
$$


19 همبستخى شاخص نياز به درمان ناهنجاريهاى فكى دندانى (ICON) با كيفيت زندگى مرتبط با ارتودنسى ...

Need), DAI (Dental Aestatic Index), PAR (Peer (Index of Complexity, ) ICON, Assessment Index) ICON شاخص IV-9] Outcome, \& Need است به كونهاى كه كارآيى آن در اين زمينه به طور كامل مورد تأييد قرار نكرفته است و همرجنين امكان بررسى همزمان نياز

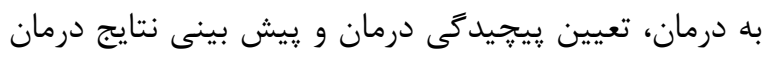

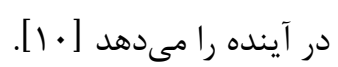

يرسشنامههاى سنجش كيفيت زندگى وابسته به شرايط دندانى -صورتى فرد كه در عين حال تأثير روانى زيبايى دندانى را در نظر بخيرند، ابزارهاى مفيدى در راستاى غربالگرى بيماران مىباشند. استفاده از اين ابزارها باعث مى مشكلات بيمار در اولويت قرار گيرد و به تصميمگيرى صحيح بيمار جهت درمان ارتودنسى كمك شايانى مىنمايند [11]. براى بررسى جنبههايى از كيفيت زندكى كه متأثر از شرايط Orthognathic فكى -دندانى هستند، از يرسشنامه استاندارد كه توسط Cunningham ارائه Cuality of Life (OQOL) شد، استفاده مىشود كه روايى و پايايى ترجمه فارسى اين

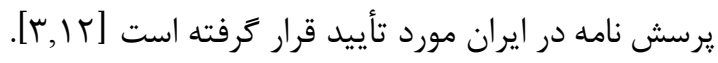
در مطالعه Liu Z و همكاران [rاس] به بررسى تأثير نياز به درمان ارتودنسى بر كيفيت زندگى يرداختند و به وجود رابطه بين اين دو جزء اشاره نمودند و همرجنين نياز به وجود روشى استاندارد جهت بررسى اين ارتباط را نيز مشخص نمودند. عوامل اجتماعى و فرهنكَ در هر منطقه در كيفيت زندگى افراد نقش داشته و مطالعات يِيشين در كشورهاى مختلف نتايج متفاوتى را براى Malocclusion (ناهنجارى روابط فى

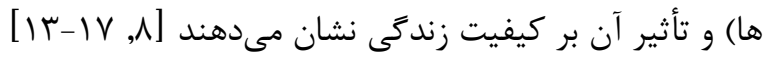

كيفيت زندگى مفهومى مبهم و خلاصه است كه در رشته هاى مختلف مورد استفاده قرار مى گيرد [ [ ]. سازمان بهداشت جهانى كيفيت زندگى را به عنوان درك مردم از زندگى خود با توجه به فرهنگ، ارزشها، اهداف، انتظارات و نكرانىهاى آنها بيان كرده است [ץ]. يكى از جنبههاى كيفيت زندكى، كيفيت زندگى مرتبط با سلامت است كه به صورت "عدم تأثير منفى شرايط دهانى روى زندكى اجتماعى و احساس مثبت فرد از شرايط دندانى- صورتى خود" تعريف مىشود [ب]. سلامت دهان و دندان به طور جدى بر روى كيفيت زندگى تعداد زيادى از افراد تأثير مى گذارد و ممكن است بر روى جنبههاى مختلفى از زندگى شامل عملكرد، اعتماد به نفس، روابط بين فردى و فرصتهاى شغلى تأثير بحذارد [^]. در بين مشكلات دهانى - دندانى Malocclusion بيشتر از سايرين به طور معنى دارى باعث كاهش كيفيت زندگى افراد مىشود [عه]]. بنابراين منطقى به نظر مىرسد كه انتظار داشت درمان ارتودنسى منجر به تقويت اعتماد به نفس و كاهش اضطراب در موقعيتهاى اجتماعى شود [ه]]. با توجه به اين كه تشخيص نياز به درمان ارتودنسى اكثراً به صورت توصيفى و كيفى مىباشد، جهت برنامه ريزى براى انجام درمان ارتودنسى و طراحى مناسب براى استفاده از منابع مالى و انسانى، بررسى نياز به درمان ارتودنسى به صورت كمى و عددى داراى اهميت ويزه بوده و تاكنون شاخصهاى متعددى براى ارزيابى نياز به درمان ارتودنسى بر اساس Malocclusion كرفتهاند؛ از جمله شاخصهاى IOTN (Index Of Treatment 
تأييد استاد داراى آنومالىهاى كرانيوفاسيال و سندرميك مانند شكاف لب و كام تشخيص داده شدند از مطالعه خارج كرديدند [1/]]. در نهايت از ميان آنها دانشآموزانى كه والدين آنها فرم رضايتنامه را امضاء نمودند، به تعداد VV I I دانش آموز يسر وارد مطالعه شدند. براى بررسى جنبههايى از كيفيت زندگى كه متأثر از شQ شرايط فكى -دندانى هستند از يرسشنامه استاندارد OQ كه توسط Cunningham ارائه شد استفاده كرديد [ץ]. ترجمه يرسشنامه "كيفيت زندگى مرتبط با ارتودنسى"، كه روايى و "ايايى ترجمه فارسى اين :رسشنامه در ايران مورد تأييد قرار كرفته است، [1 I]]، حاوى دو بخش سؤالات عمومى شامل سن، تحصيلات والدين، نوع مدرسه، تعداد فرزندان خانواده و Tr سؤال اختصاصى در زمينه كيفيت زندكى در رابطه با وضعيت دندانها است اين يرسشنامه بر اساس ارتباط بين اين سؤالها در جهار حيطه مجزا در نظر گرفته شده است كه شامل جنبه اجتماعى، زيبايى دندانى-صورتى، عملكرد دهانى و آكاهى از زيبايى دندانى -صورتى مىباشد؛ سؤالات طيفى از نمرات · تا f داشتند كه · نشان دهنده اين بود كه "اين موضوع در رابطه با شما صادق نيست" و f نشان دهنده "موضوع سوال شما را آزار مىدهد" بود؛ نمره بالاتر و پايين تر به ترتيب نشان دهنده OQOL ضعيفتر و بهتر مىباشد.

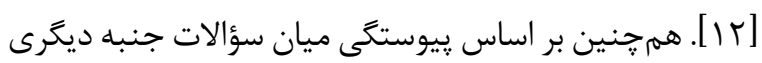
از كيفيت زندگى تحت عنوان "اعتماد به نفس" نيز به عنوان يك حيطه مجزا بررسى گرديد [1/]]. قبل از شروع تكميل يرسشنامه توضيحات لازم ارائه و از دانش آموزان خواسته شد كه برسش نامه را بر اساس نظرات
كمبود مطالعات بومى صورت گرفته در اين زمينه، ما را برآن داشت تا به تعيين رابطه نياز به درمان ارتودنسى با كيفيت زندگى در دانشآموزان يسر عا تا \1 ساله در شهر رفسنجان

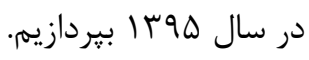

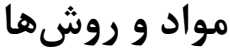

اين مطالعه مقطعى از نوع توصيفى، يس از اخذ مجوز كميته اخلاق در يزوهش دانشخاه علوم يزشكى رفسنجان (كد اخلاق: IR.RUMS.REC.1395.67 ) در مدارس يسرانه شهر رفسنجان در سال هوسا اجرا شد. شركت كنند نمونه گيرى تصادفى جند مرحلهاى از ميان دانشآموزان 1 تا تا 11 ساله مدارس رفسنجان انتخاب شدند، به اين ترتيب كه ابتدا به طور تصادفى تعدادى از مدارس دولتى دوره دوم متوسطه انتخاب شدند، سيس در هر مدرسه انتخابى، از ميان كلاسهاى موجود براى هر بايه تحصيلى، به طور تصادفى يك كلاس انتخاب شد و دانش آموزان هر كلاس جهت بررسى شرايط ورود به مطالعه معاينه شدند. فرمول تعيين حجم نمونه

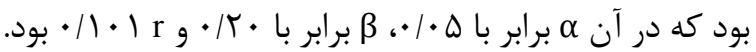
$n=\left(\frac{Z_{1-\frac{\alpha}{2}}+Z_{1-\beta} \times \sqrt{1-r^{2}}}{r}\right)^{2}+2$

سِيس از ميان آنها با توجه به سابقه برونده يزشكى آنها در مدرسه، دانش آموزانى كه داراى اختلالات روانى مانند افسردگى، شخصيت دوقطبى يا اختلال خود زشت انغارى باشند و نيز دانش آموزانى كه (body dysmorphic disorder) تاريخجه درمان ارتودنسى را ذكر كردند و يا در زمان مطالعه تحت درمان بودند و همرجنين دانش آموزانى كه در طى معاينه در اتاق با نور كافى توسط دو دانشجوى دندانيزشكى و با 


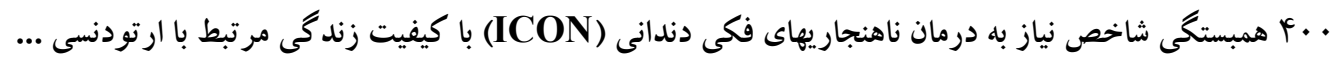

شخصى خود تكميل نمايند؛ در زيايان يرسش نامه، سؤالى از بهبود زيبايى ظاهرى خود دارند؟" و از آنها خواسته شد كه با

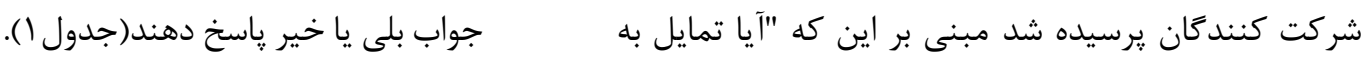

انجام درمان ارتودنسى براى بهبود شرايط فكى - دندانى و يا

جدول | بنج حيطه كيفيت زندكى ارتوكناتيك در توجمه فارسى برسشنامه I IOOQOL

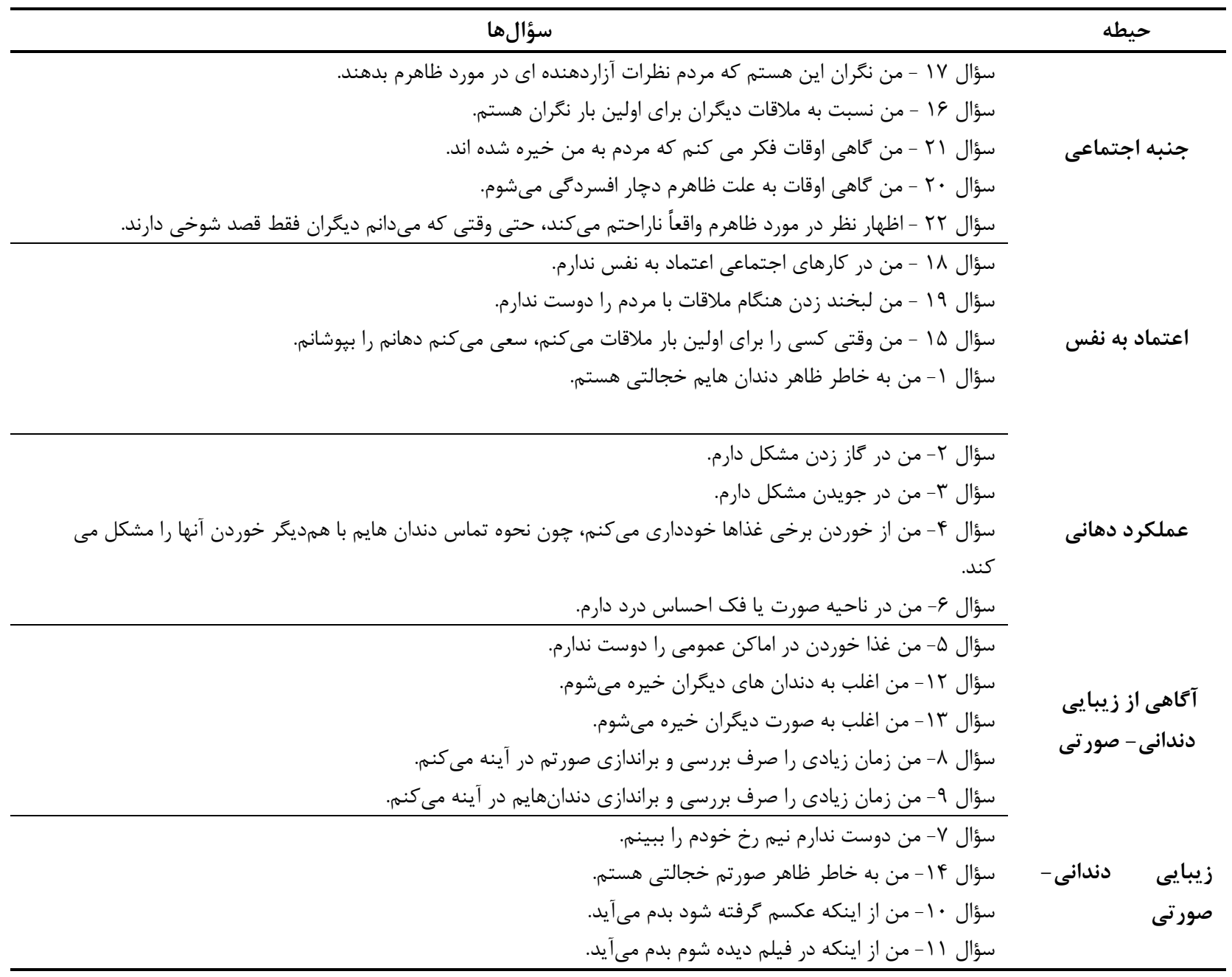

overbite و رابطه عرضى نواحى باكال بررسى شدند. طبق راهنما و جدول ICON تمام اجزاى ايندكس در ضريب ارزش مخصوص به خود ضرب شده و در نهايت حاصل جمع آنها رتبه ICON هر بيمار را مشخص نمود كه رتبه بالاتر از r
سيس تمام دانش آموزان بر اساس اجزاء ايندكس نياز به درمان ارتودنسى (ICON) توسط دانشجويانى كه از قبل كاليبره شده بودند، به وسيله آينه يكبار مصرف، معاينه و نتايج در فرم ICON ثبت شدند. در ايندكس ICON زيبايى دندانها، crowding و spacing در قوس فك بالا، crossbite، 


$$
\begin{aligned}
& \text { طبق دستور العمل خود يرسش نامه نياز به درمان ارتودنسى را } \\
& \text { نشان مىداد [•r-9 1] (جدول ؟). }
\end{aligned}
$$

\begin{tabular}{|c|c|c|c|c|c|c|c|}
\hline \multicolumn{7}{|c|}{ امتياز } & \multirow{2}{*}{ اجزا } \\
\hline ضريب & $\Delta$ & r & r & r & 1 & $\cdot$ & \\
\hline v & \multicolumn{6}{|c|}{ امتياز از 1 تا • } & ا - ارزيابى زيبايى \\
\hline$\Delta$ & > > ميلىمتر & ميلى متر & ميلى & ميلىمتر & ا / تا ه ميلىمتر & T> r> ميلىمتر & 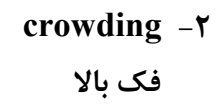 \\
\hline$\Delta$ & دندان نهفته & & >9 ميلىمتر & ميلى متر & 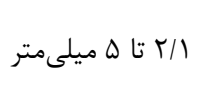 & T> Y ميلىمتر & Spacing فك بالا \\
\hline$\Delta$ & & & & & $\begin{array}{c}\text { داراى } \\
\text { Crossbite }\end{array}$ & بدون Crossbite & Crossbite $-r$ \\
\hline q & & > > ميلىمتر & ميلى متر & ميلىمتر & > ميلىمتر & Edge to edge & $\begin{array}{l}\text { Incisor }-F \\
\text { openbite }\end{array}$ \\
\hline$r$ & & & يوشش كامل & بيش از بَّ تا تا بي كامل & لَ تا بَ يوشش & كمتر از إل يُوشش & $\begin{array}{l}\text { Incisor } \\
\text { overbite }\end{array}$ \\
\hline r & & & & $\begin{array}{l}\text { Cusp to } \\
\text { cusp }\end{array}$ & $\begin{array}{l}\text { Cusp to } \\
\text { embrasure } \\
\text { only Class I, } \\
\text { II or III }\end{array}$ & $\begin{array}{c}\text { Cusp to } \\
\text { embrasure } \\
\text { only Class I, II } \\
\text { or III }\end{array}$ & $\begin{array}{c}\text { Buccal - } \Delta \\
\text { segment } \\
\text { antero- } \\
\text { posterior } \\
\end{array}$ \\
\hline
\end{tabular}

\section{جدول r - راهنماى /متيازدهى ICON}

بررسىها نشان داد كه ميانگين تعداد فرزندان خانوادهها

T///

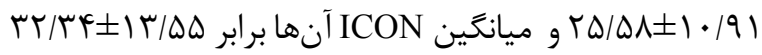

بود. بررسى همبستخى بين OQOL و ICON دانش آموزان

نشان داد كه اين دو متغير در همه سنين مورد مطالعه داراى

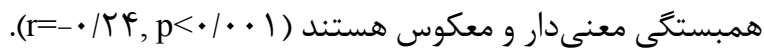

در بين هر دو گروه دانش آموزانى كه تمايل به درمان

ارتودنسى داشتند يا نداشتند همبستكى بين ICON و OQOL

معنى ار بود. در جدول گ ضريب همبستگى بين ICON و

OQOL بر حسب متغيرها نشان داده شده است.

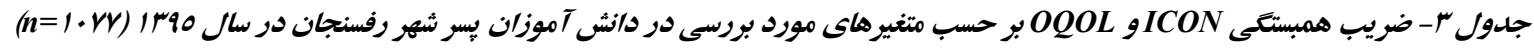

اطلاعات يرسشنامهها و فرمها پٍ از جمع آورى توسط

نرمافزار آمارى SPSS نسخه اب مورد تجزيه و تحليل قرار

كَرفت. نتايج براى ICON و OQOL دانشآموزان مورد بررسى

به صورت "انحراف معيار 土 ميانگين" كزارش شد سيس به

منظور ارزيابى رابطه نياز به درمان ارتودنسى و كيفيت زندگى

مرتبط با ارتودنسى بر حسب متغيرهاى مورد بررسى، از ضريب

همبستخى يِيرسون (Pearson) استفاده شد. سطح معنى دارى

در آزمونها هـ • • در نظر ترفته شد.

نتايج 
r r r همبستخى شاخص نياز به درمان ناهنجاريهاى فكى دندانى (ICON) با كيفيت زندگى مرتبط با ارتودنسى ...

\begin{tabular}{|c|c|c|c|c|}
\hline \multirow{2}{*}{ 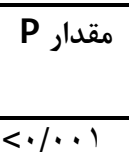 } & \multirow{2}{*}{ 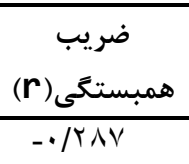 } & \multirow{2}{*}{ (درصد) تعداد } & \multicolumn{2}{|c|}{ متغير } \\
\hline & & & 19 & سن (سال) \\
\hline$<\cdot / . .1$ & $-\cdot / 119$ & rov (rT/l) & IV & \\
\hline.$/ 1$ & -.rTO & $1 \wedge \Lambda(1 \vee / \Delta)$ & 11 & \\
\hline$<\cdot / \cdot \cdot 1$ & $-\cdot / 4 r q$ & THI (TI/4) & 1 & تعداد فرزندان \\
\hline$<\cdot / \cdots 1$ & $-\cdot / K r$. & $F Y F(F F / \cdot)$ & r & \\
\hline$<\cdot / \cdots 1$ & $-\cdot / K I T$ & $|r|(1 / K)$ & r & \\
\hline$\cdot / \cdot 1 \wedge$ & $-\cdot / 1 \Delta F$ & $99(9 / \Upsilon)$ & r & \\
\hline ./.r. & $-\cdot / r \wedge 9$ & $\operatorname{Fr}(r / \Lambda)$ & $>r$ & \\
\hline$\cdot / \cdot 1$ &.$- / A A r$ & rQ9 (YV/D) & كمتر از دييلم & تحصيلات بِدر \\
\hline.$/ \cdot r^{\prime}$ &.$- / 110$ & $r q \cdot(r r / r)$ & دييلم & \\
\hline.$/ 148$ & $-\cdot / 1 \cdot 9$ & $\operatorname{lVA}(19 / 0)$ & فوق دييلم & \\
\hline$<\cdot / \cdot \cdot 1$ & $-\cdot / F T$. & $1 \wedge \wedge(1 \vee / \Delta)$ & ليسانس & \\
\hline$\cdot / . .1$ & $-\cdot / 4 r q$ & $\Delta \Delta(\Delta)$ & فوق ليسانس و بالاتر & \\
\hline •ハr. & $-\cdot / r \vee \Lambda$ & $191(1 / / 4)$ & كمتر از دييلم & تحصيلات مادر \\
\hline$<\cdot / \cdot \cdot 1$ & $-\cdot / r \cdot r$ & $r \Delta S(r / 1)$ & دييلهم & \\
\hline$<\cdot / l f T$ & $-\cdot / \cdot 19$ & TQT (TV/I) & فوق دييله & \\
\hline$\cdot|\cdot F|$ & $-\cdot / 1 \Delta \varphi$ & $\operatorname{IVT}(|\varepsilon| \cdot)$ & ليسانس & \\
\hline$\% v$ &.$- / \mu k \Delta$ & $\Delta 9(\Delta / \Delta)$ & فوق ليسانس و بالاتر & \\
\hline$<\cdot / \cdot, 1$ & $-\cdot / r r$. & Vq $(V F / \cdot)$ & خير & تمايل به ارتودنسى \\
\hline$<\cdot / \cdot \cdot 1$ & $-\cdot / T \Delta q$ & $r \Lambda \cdot(r \varepsilon \mid \cdot)$ & بله & \\
\hline$<\cdot / \cdots$, & $-\cdot / r V a$ & $9 \Delta 9(91 / \pi)$ & دولتى & نوع مدرسه \\
\hline$<\cdot / \cdots 1$ & $-.11 \cdot 9$ & $F \mid \Lambda(r N / \Lambda)$ & غير دولتى & \\
\hline
\end{tabular}

نتايج مطالعه حاضر نشان مىدهد كه نمره كيفيت زندگى

مرتبط با سلامت دهانى و شاخص نياز به درمان ناهنجارىهاى ارتودنسى در دانش آموزان دبيرستانى رفسنجان داراى همبستخى معكوس مىباشند. عوامل مختلفى تعريف كيفيت زندگى را تحت تأثير قرار مىدهند، اين عوامل در دو گروه اجتماعى و فردى قابل بررسى است؛ نتايج متفاوت مطالعات مختلف در ارتباط با كيفيت زندگى نيز مرتبط با اين مقولهها

مىباشد.
امروزه تعداد زيادى از افراد جامعه متمايل به انجام درمان ارتودنسى به منظور بهبود مشكلات روانى-جتماعى مرتبط با زيبايى هستند. علاوه بر اين، (psychosocial) مطالعات اخير بر اين نكته تأكيد دارند كه ناهنجارىهاى فكى به وضوح در اعتماد به نفس افراد در برخوردهاى اجتماعى

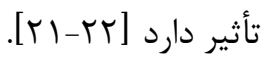


در مورد كودكان و نوجوانان OQOL داراى اهميت بسيار

بالايى است جرا كه كودكان و نوجوانان از لحاظ روانى، اجتماعى و ادراكى به صورت مداوم در حال تكامل و تغيير مىباشند همرجنين اختلال عملكرد فعلى آنان مىتواند بر تكامل روانى - اجتماعى آنان در آينده تأثير گذار باشد. هنگًامى كه يك ابزار براى سنجش در يك كشور انتخاب مىشود بايستى درحالى كه ويزگى هاى روانشناسى قابل قبول ارائه مى كند، از لحاظ فرهنكَى نيز براى آن جامعه معتبر باشد. Danaei نفس، زيبايى دندانى-صورتى و آكاهى از زيبايى دندانى-

صورتى عوامل مؤثر در زندگى نوجوانان هستند [1 I ]. در مطالعه حاضر همبستگى بين OQOL و ICON مورد بررسى قرار گرفته است، دليل بررسى شاخص ICON در اين مطالعه آن است كه اين شاخص نسبت به ديخر شاخصها جديدتر و كاملتر است. در ميان شاخصهاى قديمىتر IOTN از اعتبار بيشترى برخوردار بود، اما ICON به عنوان جايكزين اين شاخص مورد بررسى قرار گرفت. برترى ICON نسبت به شامل امكان بررسى همزمان نياز به درمان، تعيين IOTN ״يجيدگ است در حالى كه IOTN تنها نياز به درمان ارتودنسى را بررسى مى كند. علاوه بر اين موارد در شاخص ICON تاكيد بيشترى بر بررسى دندانهاى قدامى نسبت به دندانهاى خلفى وجود دارد كه اين دندانها ظاهر صورتى را بيشتر تحت تأثير قرار مىدهند [rه]]. مطالعه Chen نشان داد درمان ارتودنسى مىتواند اثر متناقضى بر روى ميزان OQOL داشته باشد كه البته رابطه معكوس ICON و OQOL به طور موقتى
همسو با نتايج مطالعه حاضر در مطالعات مختلفى از جمله مطالعه Tajima و Marques نيز همزمان با افزايش مشكلات دهانى - دندانى ميانخين نمره كيفيت زندگى كاهش مىيابد [rז, ז [1]. از طرفى نتيجه مطالعه Kenealy و همكاران نشان داد كه بزرگسالانى كه در كودكى تحت درمان ارتودنسى قرار گَرفتهاند، از نظر كيفيت زندگى با بزرگسالان گروه كنترل تفاوتى نداشتند. در اين مطالعه كه با نتايج مطالعه حاضر هم خوانى ندارد، افزايش كيفيت زندكى را در ارتباط با انجام ارتودنسى كزارش نمى كند [rY]. در توجيه اختلافات موجود در نتايج مطالعات مختلف دو نكته مد نظر است: اولاً سن جمعيت مورد ارزيابى در مطالعات ذكر شده و ديكر مطالعات مشابه جمعيت مورد بررسى داراى ميانگين سنى متفاوت مى

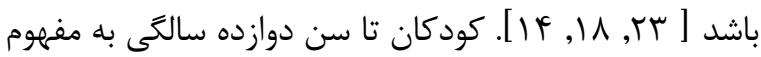
سلامت به عنوان يك مقوله جند بعدى مىنكرند و در محدوده 1 1 1 ا سال قادر خواهند بود OQOL خود را با توجه به اثرات آن روى عملكرد روزانه خود ارزيابى كنند كه اين موضوع مى تواند توجيه انتخاب اين گروه سنى در اين مطالعه باشد، ثانياً روش ارزيابى كيفيت زندگى؛ به دليل اهميت زياد مقوله كيفيت زندگى ابزارهاى سنجش فراوانى، طى ساليان اخير ارائه و بررسى شده است. براى مثال در مطالعه Chaitra از شاخص كيفيت زندگى مرتبط با سلامت براى بررسى كيفيت زندگى كلى بدن در ارتباط با نياز به درمان ارتودنسى استفاده شده است، در حالى كه به نظر مىرسد درمان ارتودنسى تأثير قابل توجهى بر روى ديخر اركانهاى بدن نداشته باشد و بيشتر مرتبط با سلامت دهان و دندان باشد [.r] 


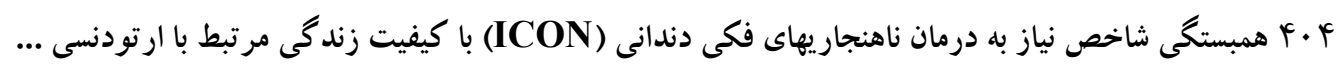

احساس خجالت مىكنند و ممكن است برداشتهاى فردى مرتبط با ظاهر صورتى - دندانى خود داشته باشند. درك و دريافت افراد مختلف از Malocclusion متفاوت است و ممكن است آكاهى يك فرد از وجود Malocclusion به شدت آن ربطى نداشته باشد و همين موارد باعث ايجاد تفاوت در تقاضاى درمان ارتودنسى توسط افراد مختلف مىشود [Tr,

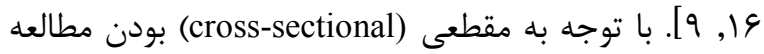
حاضر پيشنهاد مىشود، بررسى بر روى كيفيت زندگى در مقاطع مختلف قبل از درمان و بعد از درمان، انجام شود. هم:جنين با تفكيك اجزاء ايندكس ICON و بررسى رابطه جزء زيبايى آن با ديگر اجزاء مىتوان نتايج مطلوبترى حاصل كرد.

\section{نتيجه}

جنبdهاى مختلف كيفيت زندگى مى تواند بر تمايل به انجام درمان ناهنجارىهاى فكى صورتى و ارتودنسى بين نوجوانان تأثير گذار باشد. همرجنين درمان ارتودنسى تأثير به سزايى بر احساس زيبايى فرد كذاشته و باعث افزايش اعتماد به نفس و در نتيجه افزايش كيفيت زندكى نوجوان خواهد شد.

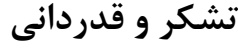

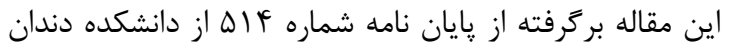

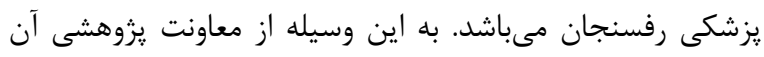

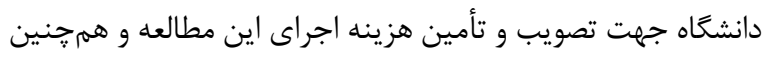

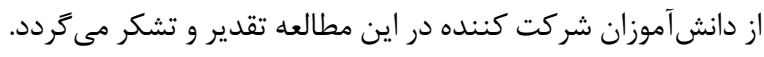

و در يك ماه ابتدايى حضور إيلاينس ارتودنسى در دهان بيمار وجود داشت، به همين منظور افراد در حال انجام درمان ارتودنسى از مطالعه حاضر خارج شدند [عr]. برخى محدوديتهاى اجتماعى را هم مىتوان در نتايج مطالعات تأثير كذار دانست. جنسيت افراد مورد مطالعه يكى از اين عوامل است. در مطالعه Momeni عليرغم اين كه رابطه مشخصى بين OQOL و وجود ندارد اما ميانگين نمره OQOL ICON تأثير جنسيت است و نشان مىدهد مشكلات زيبايى دهانىدندانى تأثير بيشترى بر كاهش روابط اجتماعى دختران دارد [rV] [بر مطالعه حاضر به علت محدوديتهاى اجتماعى تنها يسران مورد بررسى قرار گرفتند كه به نظر مىرسد در نتايج تأثير گذار باشد. از طرفى تعداد كم شركت كنندگًان در مطالعه ممكن است منشأ اختلاف نتايج آن با مطالعه حاضر Momeni باشد و شايد بتوان گفت به علت جامعه آمارى بالا در مطالعه حاضر، رابطه معنى دار و معكوس بين ICON و OQOL حاصل شده است [N1]]. نتايج مطالعه حاضر و ساير مطالعات نشان مىدهد كه مشكلات دهان و دندان روى جنبههاى روانى، اجتماعى و وضعيت بيمار تأثيرگذار هستند و مشخصاً مى سى تواند كيفيت زندگى و جنبههاى مههم زندگى فرد را از طريق اختلال در حضور اجتماعى و روابط بين فردى تحت تأثير قرار دهند. از طرفى مشخص شده كه اغلب افراد داراى Mاى مختلف در موقعيتهاى اجتماعى 


\section{References}

[1] Bowling A, Rowe G, Adams S, Sands P, Samsi K, Crane M, et al. Quality of life in dementia: a systematically conducted narrative review of dementia-specific measurement scales. Aging \& Mental Health 2015; 19(1): 13-31.

[2] WHOQoL Group. The development of the World Health Organization quality of life assessment instrument (the WHOQOL). InQuality of life assessment: International perspectives. Berlin, Heidelberg, Springer. 1994: 41-57.

[3] Cunningham SJ, Hunt NP. Quality of life and its importance in orthodontics. J orthod 2001; 28(2): $152-$ 8.

[4] Nagarajappa R, Ramesh G, Sandesh N, Lingesha R-T, Hussain M-A-Z. Impact of fixed orthodontic appliances on quality of life among adolescents' in India. J Clin Exp Dent 2014; 6(4): e389.

[5] Rusanen J, Lahti S, Tolvanen M, Pirttiniemi P. Quality of life in patients with severe malocclusion before treatment. EJO 2009; 32(1): 43-8.

[6] Rossini G, Parrini S, Castroflorio T, Fortini A, Deregibus A, Debernardi CL. Children's perceptions of smile esthetics and their influence on social judgment. Angle Orthod 2016; 86(6): 1050-5.
[7] Kiyak HA, editor Cultural and psychologic influences on treatment demand. Semin Orthod 2000; 6(4): 242-8.

[8] Phillips C, Beal KNE. Self-concept and the perception of facial appearance in children and adolescents seeking orthodontic treatment. Angle Orthod 2009; 79(1): 126.

[9] Feu D, de Oliveira BH, de Oliveira Almeida MA, Kiyak HA, Miguel JAM. Oral health-related quality of life and orthodontic treatment seeking. Am J Orthod Dentofacial Orthop 2010; 138(2): 152-9.

[10] Torkan S, Pakshir HR, Fattahi HR, Oshagh M, Danaei SM, Salehi $\mathrm{P}$, et al. An analytical study on an orthodontic index: Index of Complexity, Outcome and Need (ICON). Int J Dent 2015; 16(3): 149.

[11] Javidi H, Vettore M, Benson PE. Does orthodontic treatment before the age of 18 years improve oral health-related quality of life? A systematic review and meta-analysis. Am J Orthod Dentofacial Orthop 2017; 151(4): 644-55.

[12] Danaei SM, Fijan S, Mohammadi N, Soleimanzadeh R. Assessment of the Reliability and Validity of the Farsi Translation of the "Orthognathic Quality of Life Questionnaire" in 10-14 Year-Olds in Shiraz. JIDAI 2014; 26(1): 1 . 
[13] Liu Z, McGrath C, Hägg U. The impact of malocclusion/orthodontic treatment need on the quality of life: a systematic review. Angle orthod 2009; 79(3): 585-91.

[14] Marques LS, Ramos-Jorge ML, Paiva SM, Pordeus IA. Malocclusion: esthetic impact and quality of life among Brazilian schoolchildren. Am J Orthod Dentofacial Orthop 2006; 129(3): 424-7.

[15] Bernabé E, Flores-Mir C, Sheiham A. Prevalence, intensity and extent of Oral Impacts on Daily Performances associated with self-perceived malocclusion in 11-12-year-old children. BMC Oral Health 2007; 7(1): 6.

[16] Bernabé E, Sheiham A, Tsakos G, Messias de Oliveira C. The impact of orthodontic treatment on the quality of life in adolescents: a case-control study. EJO 2008; 30(5): 515-20.

[17] Gazit-Rappaport T, Haisraeli-Shalish M, Gazit E. Psychosocial reward of orthodontic treatment in adult patients. EJO 2010; 32(4): 441-6.

[18] Danaei SM, Soleymanzade R, Mohammadi N, Fijan S. Association between orthodontic treatment willingness and its related quality of life in 10-14 year-old adolescents in Shiraz. JIDS 2013; 9(5): 442-50.[Farsi]
[19] Firestone AR, Beck FM, Beglin FM, Vig KW. Validity of the Index of Complexity, Outcome, and Need (ICON) in determining orthodontic treatment need. Angle Orthod 2002; 72(1): 15-20.

[20] Chaitra K, Reddy N, Suga Reddy V. Orthodontic treatment: need and demand in north karnataka school children. JCDR 2014; 8(5): ZC37.

[21] dos Santos Oliveira R, Flório FM, Oliveira AMG. SelfPerception of Brazilian Adolescents who need Orthodontic Treatment. Pesqui Bras Odontopediatria Clin Integr 2018; 18(1): 3729.

[22] de Couto Nascimento V, de Castro Ferreira Conti AC, de Almeida Cardoso M, Valarelli DP, de AlmeidaPedrin RR. Impact of orthodontic treatment on selfesteem and quality of life of adult patients requiring oral rehabilitation. Angle Orthod 2016; 86(5): 839-45.

[23] Tajima M, Kohzuki M, Azuma S, Saeki S, Meguro M, Sugawara J. Difference in quality of life according to the severity of malocclusion in Japanese orthodontic patients. Tohoku J Exp Med 2007; 212(1): 71-80.

[24] Kenealy PM, Kingdon A, Richmond S, Shaw WC. The Cardiff dental study: a 20-year critical evaluation of the psychological health gain from orthodontic treatment. Br J Health Psychol 2007; 12(1): 17-49. 
[25] Heravi F, Farzanegan F, Tabatabaee M, Sadeghi M. Do malocclusions affect the oral health-related quality of life? Oral Hlth Prev Dent 2011; 9(3): 229-33.

[26] Chen M, Wang D-W, Wu L-P. Fixed orthodontic appliance therapy and its impact on oral health-related quality of life in Chinese patients. Angle Orthod 2010; 80(1): 49-53.
[27] Momeni Danaei S, Zarifnajafi H, Nabavizade Rafsanjani A, Fakhri F, Bahramnia F, Sardarian A, et al. Evaluating the relationship between Orthodontic Treatment need and Oral Health-Related Quality of life Among students aged 15-18 year in Shiraz. 3dj 2015; 4(2): 20-3. 


$$
\text { 1 • • همبستخى شاخص نياز به درمان ناهنجاريهاى فكى دندانى (ICON) با كيفيت زندگى مرتبط با ارتودنسى ... }
$$

\title{
Correlation of the Index of Orthodontic Treatment Need (ICON) and Orthodontic-Related Quality of Life in Male Students in Rafsanjan City in 2016: A Descriptive Study
}

\author{
P. Abedi ${ }^{1}, \underline{\text { A. Nabavizadeh Rafsanjani }}{ }^{2}$, S. Fijan $^{3}$, P. Ansari ${ }^{4}$, M. Sanji ${ }^{5}$
}

Received: 28/05/2019 Sent for Revision: 09/07/2019 Received Revised Manuscript: 06/06/2019 Accepted: 08/06/2020

Background and Objectives: One aspect of quality of life is its association with health promotion. Evaluation of the need for orthodontic treatment is of particular importance and ICON (Index of Complexity, Outcome and Need) is one of the indicators to evaluate this case. Therefore, the aim of this study was to investigate the corelation between the orthodontic treatment need and orthodontic-related of quality of life among male students aged 16-18 years in Rafsanjan city.

Materials and Methods: This descriptive study was performed on 1077 students selected by multistage random sampling from Rafsanjan schools in 2016. The Orthognathic Quality of Life (OQOL) questionnaire was used to assess the quality of life of students. All students examined based on ICON elements and the results were registered on ICON form. Data were analyzed using Pearson's correlation coefficient.

Results: Quality of life mean and standard deviation was $25.58 \pm 10.91$ and ICON mean and standard deviation was $32.34 \pm 13.55$ which both had a significant inverse correlation $(\mathrm{p}<0.001, \mathrm{r}=-0.24)$.

Conclusion: The results show that different aspects of quality of life can affect the tendency to treat maxillofacial and orthodontic disorders among adolescents and orthodontic treatment has a significant effect on increasing self-esteem and thus on adolescents quality of life.

Key words: Quality of life, Orthodontics, ICON, Rafsanjan

Funding: This research was funded by Research Deputy of Rafsanjan University of Medical Sciences.

Conflict of Interest: None declared.

Ethical approval: The Ethics Committee of Rafsanjan University of Medical Sciences approved the study (Ethics number: IR.RUMS.REC.1395.67)

How to cite this article: Abedi P, Nabavizadeh Rafsanjani A, Fijan S, Ansari P, Sanji M. Correlation of the Index of Orthodontic Treatment Need (ICON) and Orthodontic-Related Quality of Life in Male Students in Rafsanjan City in 2016: A Descriptive Study. J Rafsanjan Univ Med Sci 2020; 19 (4): 397-408. [Farsi]

\footnotetext{
1-- Dentistry Student, Student Research Committee, Rafsanjan University of Medical Sciences, Rafsanjan, Iran, ORCID:0000-0003-38344207

2- Assistant Prof., Dept. of Orthodontics, Dentistry Faculty, Rafsanjan University of Medical Sciences, Rafsanjan, Iran, ORCID:0000-00021043-2427.

(Corresponding Author) Tel: (034) 34281894 , Fax: (034) 34281894, E-mail: alinabavizadeh@gmail.com

3- Assistant Prof., Dept. of Pediatric Dentistry, Dentistry Faculty, Islamic Azad University, Shiraz Branch, Shiraz, Iran, ORCID:0000-0003$3362-1770$

4 Dentist, Kerman, Iran, ORCID:0000-0002-0410-2755

5- Dentist, Kerman, Iran, ORCID:0000-0001-6890-2738
} 